\title{
Initiation of Basal Insulin in Patients with Uncontrolled Type 2 Diabetes Mellitus
}

\author{
Muneer Salih Muneer \\ Department of Internal Medicine, Nile University, Khartoum North, Sudan \\ Email: monir10@hotmail.com
}

How to cite this paper: Muneer, M.S. (2020) Initiation of Basal Insulin in Patients with Uncontrolled Type 2 Diabetes Mellitus. Open Journal of Endocrine and Metabolic Diseases, 10, 89-93.

https://doi.org/10.4236/ojemd.2020.106009

Received: June 1, 2020

Accepted: June 26, 2020

Published: June 29, 2020

Copyright $\odot 2020$ by author(s) and Scientific Research Publishing Inc. This work is licensed under the Creative Commons Attribution International License (CC BY 4.0).

http://creativecommons.org/licenses/by/4.0/

(c) (i) Open Access

\begin{abstract}
Type 2 diabetes mellitus is a growing health problem, characterized by insulin resistance progressing to beta cell dysfunction and insulin deficiency, most of these patients will need intensification of treatment and initiation of insulin to delay or prevent diabetic complications. Glycemic control is the most important aspect of management, and in reducing morbidity and mortality of the diseases. Control of plasma glucose in patients with diabetes can be assessed by HbA1c, FPG, PPG, but still HbA1c\% remains the gold standard for assessment of glycemic control and follow up of diabetic patients. The aim of this study is to assess $\mathrm{HbAlc} \%$ in patients on oral anti-diabetic drugs, with poor glycemic control before and after adding basal insulin, with titration of the dose of insulin depending on fasting blood sugar. 82 patients with uncontrolled type 2 diabetes ( $43.9 \%$ male, $56.1 \%$ female), with HbAlc more than $9 \%$, on two types of oral diabetic medication or more, were started on basal insulin (glargine, lantus) and followed for three to six months. Overall $82 \mathrm{pa}-$ tients with type 2 diabetes mellitus were included in the study. The mean age of the study population was 58.4 years, the mean duration of the disease range was 13.4 years. All patients with $\mathrm{HbAlc}$ more than $9 \%$, without organ failure, were included in the study. The mean $\mathrm{HbAlc}$ overall had decreased from mean of $11.15 \%$ before starting basal insulin to the mean of $8.43 \%$ within 3 to 6 month, after initiating basal insulin, this difference was significant at $\mathrm{p}<0.001$. There was no adverse effect on this medication in any of the study group. The addition of basal insulin to oral anti-diabetic medication in uncontrolled insulin-naïve type 2 diabetic patients resulted in significant improvement of glycemic control, with improved $\mathrm{HbAlc}$ level, without adverse effects.
\end{abstract}

\section{Keywords}

T2DM-Type 2 Diabetes Mellitus, HbA1c-Haemoglobin A1c\%, FBG-Fasting Blood Glucose, PPG-Post Prandial Glucose, NPH-Neutral Protamine Hagedorn 


\section{Introduction}

Type 2 diabetes mellitus (T2DM) is a growing health problem, leading to morbidity and mortality. T2DM is characterized by insulin resistance progressing to beta cell-dysfunction and insulin deficiency. T2DM accounts for $90 \%$ of all cases of diabetes, the vast majority of patients who are on oral hypoglycemic agents are uncontrolled, with above needed target of $\mathrm{HbAlc}$ level, and the glycemic control tends to worsen over time, these patients need insulin, as their ability to produce their own insulin from pancreatic beta cells declines progressively [1].

The UK Prospective Diabetes Study (UKPDS) highlighted the progressive nature of T2DM and the need for intensification of treatment, and initiation of insulin to maintain satisfactory glycemic control [2]. Glycemic control in diabetes mellitus is needed to reduce morbidity and mortality of the disease.

Achieving good glycemic control or significantly prevent or delay the micro vascular and macro vascular complications of diabetes. Glycated hemoglobin (HbA1c) is the gold standard for assessment of glycemic control [3].

This is a prospective study for uncontrolled insulin-naïve patients with type 2 diabetes mellitus on oral hypoglycemic drugs. All patients were on metformin plus sulfonylurea (glimepiride or gliclazide) started on basal insulin (glargine-lantus), in addition to their own oral anti-diabetic drugs and followed for three to six months to see the effect on glycemic control, by assessing HbAlc before and after starting the basal insulin.

\section{Methods}

This was a prospective study conducted in Sudan, from January to June 2018, All patients attending the clinic, with uncontrolled type 2 diabetes mellitus (A1c\% more than 9\%) on two or more oral anti-diabetic drugs, agreed to receive long acting insulin were included in the study. 82 patients came for follow up, and blood test for fasting blood sugar and A1c\% were repeated, 36 (43.9\%) were male patients, and 46 (56.1\%) were female. Patients on single anti-diabetic drug, or did not come for follow up to repeat the blood test for fasting blood sugar and A1c\% were excluded from the study.

Patients were documented and started on basal insulin, 10 units of glargine insulin (lantus) nocturnal dose, titration of the dose of insulin was through checking fasting blood glucose for three days, and taking the medium of the readings, following the guideline of (Basal Insulin Titration Algorithms From World Medical Societies) (Table 1).

\section{Results}

Overall 82 patients with type 2 diabetes mellitus were included in the study 36 (43.9\%) were male, and 46 (56.1\%) were female. The mean age of the study population was 57.7 years, and duration of the disease range from 6 to 20 years with the mean of (13.2). 
Table 1. Basal insulin titration algorithms from world medical societies.

\begin{tabular}{ccccc}
\hline Measure algorithm & ADA/EASD40 & ACCE/ACE41 & IDF43 & CDA44 \\
\hline Initial dosage & $10 \mathrm{U} / \mathrm{d}$ & $10 \mathrm{U} / \mathrm{d}$ & Non specified & $10 \mathrm{U} / \mathrm{d}$ \\
Titration & $2 \mathrm{U}$ every $3 \mathrm{~d}$ & $1-3 \mathrm{U}$ every $2-3 \mathrm{~d}$ & $2 \mathrm{U}$ every $3 \mathrm{~d}$ & $1 \mathrm{U}$ every d \\
Target FBG mg/dl & $70-130$ & $<110$ & $<110$ & $72-126$ \\
Target HbA1c\% & $<7.0$ & $\leq 6.5$ & $\leq 6.5$ & $\leq 7.0$ \\
\hline
\end{tabular}

a Fasting blood glucose (FBG) target recommendation from the American Association of Clinical Endocrinologists (AACE) 2011 guidelines.

All patients with HbA1C more than 9\%, without organ failure, who agreed to start insulin, were included in the study. The mean HbAlc overall had decreased from $11.15 \%$ to $8.44 \%$ at 3 - to 6 -month follow-up, this difference was significant at $\mathrm{p}<0.001$.

Reduction of HbA1c was not related to either patient age, duration of diabetes, the level of $\mathrm{HbA1c} \%$ or the daily dose of basal insulin. The minimum dose of insulin was 10 units per day, and maximum of 25 units, (mean of 16.6 units), the dose of insulin was titrated by checking the fasting blood glucose, none of patients in the study group gave any symptoms of hypoglycemia.

\section{Discussion}

Although the pathogenesis of type 2 diabetes is mainly due to insulin resistant, but most of T2DM patients (at least 50\%) will require insulin because of beta cell dysfunction. Insulin requirement is due to failure of oral anti-diabetic drugs (OADs) to maintain good glycemic control, at the diagnosis of type 2 diabetes in the presence of metabolic decompensation and/or glycosylated hemoglobin > $9.0 \%$, or in the setting of decompensated renal or hepatic insufficiency, myocardial infarction, stroke, acute severe illness, or major surgery [1].

For patients with T2DM, those fail to get good glycemic control with OADs, ADA/EASD recommend to add basal insulin, like NPH (neutral protamine Hagedorn) insulin, insulin glargine or detemir insulin, starting with low dose (0.1 $0.2 \mathrm{U} \mathrm{kg} /$ day) and titration according to blood glucose level [4] [5].

Insulin initiation, alone or in combination with OADs, should be started sooner and not later to achieve target Alc, by controlling fasting and postprandial glucose lead to long term glycemic control. Use of a basal insulin reduces glucotoxicity by normalizing fasting glucose, and helps to preserve beta-cell function [6].

There are different approaches to initiate insulin including, basal bolus regimen with step wise intensification of insulin, multiple daily injections approach in which short acting insulin before meal will be added to basal bolus insulin (Table 2).

There are many studies for adding basal insulin to achieve the recommended $\mathrm{HbA1c}$ targets in T2DM patients inadequately controlled with oral hypoglycemic agents (OHA) [7]. 
Table 2. Showing the proportion of patients achieving HbAlc $\leq 7 \%$ at study end across several trials.

\begin{tabular}{ccc}
\hline Study (reference) & Comparators & $\begin{array}{c}\text { Proportion of patients achieving } \\
<7 \% \text { of A1c atrial end }\end{array}$ \\
\hline \multirow{2}{*}{ Riddle et al. 2003} & NPH insulin & $57 \%$ \\
Meneghini et al. 2013 & Insulin glargine & $58 \%$ \\
Fritsche et al. 2010 & Insulin glargine & $53 \%$ \\
& Insulin detemir & $38 \%$ \\
Buse et al. 2009 & Biphasic (NPH/RI or NPH/aspart) & $48 \%$ \\
& Biphasic (Lispro Mix 75:25) & $28 \%$ \\
Liebl et al. 2009 & Insulin glargine & $48 \%$ \\
& Basal-bolus (detemir/aspart) & $40 \%$ \\
& Biphasic (aspart 30:70) & $60 \%$ \\
\hline
\end{tabular}

Strict glycemic control increases the risk of hypoglycemia, so the balance needed the two conditions [8]. There are several barriers to initiation of insulin therapy. For patients, barriers include fears of injections and hypoglycemia, perceptions that use of insulin will impose lifestyle restrictions, and the beliefs for some patients that insulin use means that the disease is severe and no hope for management. Physicians barriers to starting insulin therapy include fear of potential side effects of insulin, hypoglycemia and weight gain [4]. The major benefit of basal insulin plus oral anti-diabetic regimen is its simplicity and safety, with the option of step-wise intensification, compared to basal-bolus regimen with multiple injections.

The American Diabetes Association considers HbAlc as an important indicator of long-term glycemic control, and a reliable measure of chronic hyperglycemia and correlates well with the risk of long-term diabetes complications. United Kingdom Prospective Diabetes Study (UKPDS) provides strong evidence that reducing glycated haemaglobin (HbAlc) improves long-term prognosis in terms of diabetic complications [2]. The UKPDS showed that intensive blood sugar control is associated with significant reduction in macro vascular complication, so $1 \%$ reduction of Alc level will lead to $10 \%$ reduction in myocardial infarction, and $16 \%$ reduction in stroke [9].

In this study adding basal insulin to oral anti-diabetic drugs showed significant change in glycemic control, as shown by the difference between preAlc and postA1c \%, without adverse effects as hypoglycemia. In this study, many patients did not come for follow up after getting basal insulin, because either they did not use insulin, or for other reasons so the number of patients was small. The study needs to include the following of these patients to see the prevalence of diabetic complications compared with other patients on oral di- 
abetic drugs only.

\section{Conclusion}

The addition of basal insulin to oral anti-diabetic medication in uncontrolled insulin-naïve type 2 diabetic patients resulted in significant improvement of glycemic control, with improved HbAlc level, without adverse effects.

\section{Conflicts of Interest}

The author declares no conflicts of interest regarding the publication of this paper.

\section{References}

[1] Sanlioglu, A.D., et al. (2013) Clinical Utility of Insulin and Insulin Analogs. Islets, 5, 67-78. http://www.ncbi.nlm.nih.gov/pmc/articles/PMC4204021/ https://doi.org/10.4161/isl.24590

[2] UK Prospective Diabetes Study Group (1995) UK Prospective Diabetes Study 16: Overview of 6 Years' Therapy of Type II Diabetes: A Progressive Disease. Diabetes, 44, 1249-1258. https://doi.org/10.2337/diab.44.11.1249

[3] Belay, E., et al. (2015) Correlation of Fasting and Postprandial Plasma Glucose with HbA1c in Assessing Glycemic Control; Systematic Review and Meta-Analysis. Archives of Public Health, 73, Article No. 43. https://doi.org/10.1186/s13690-015-0088-6

[4] Rubino, A., et al. (2007) Delayed Initiation of Subcutaneous Insulin Therapy after Failure of Oral Glucose-Lowering Agents in Patients with Type 2 Diabetes: A Population-Based Analysis in the UK. Diabetic Medicine, 24, 1412-1418. https://doi.org/10.1111/j.1464-5491.2007.02279.x

[5] Arnolds, S., et al. (2013) Common Standards of Basal Insulin Titration in T2DM. Journal of Diabetes Science and Technology, 7, 771-788.

http://www.ncbi.nlm.nih.gov/pmc/articles/PMC3869146/ https://doi.org/10.1177/193229681300700323

[6] Rosenstock, J. (2004) Basal Insulin Supplementation in Type 2 Diabetes: Refining the Tactics. The American Journal of Medicine, 116, 10S-16S.

https://doi.org/10.1016/j.amjmed.2003.12.004

[7] Lee, B.-W., et al. (2017) Insulin Therapy for Adult Patients with Type 2 Diabetes Mellitus: A Position Statement of the Korean Diabetes Association, 2017. The Korean Journal of Internal Medicine, 32, 967-973. https://doi.org/10.3904/kjim.2017.314

[8] Vora, J. et al. (2015) Intensifying Insulin Regimen after Basal Insulin Optimization in Adults with Type 2 Diabetes: A 24-Week, Randomized, Open-Label Trial Comparing Insulin Glargine Plus Insulin Glulisine with Biphasic Insulin Aspart (LanScape). Diabetes, Obesity \& Metabolism, 17, 1133-1141.

http://www.ncbi.nlm.nih.gov/pubmed/26085028 https://doi.org/10.1111/dom.12528

[9] Laakso, M. (1999) Benefits of Strict Glucose and Blood Pressure Control in Type 2 Diabetes. Circulation, 99, 461-462. http://circ.ahajournals.org/content/99/4/461 https://doi.org/10.1161/01.CIR.99.4.461 